\title{
El ingreso de China a la OMC y su impacto sobre los países de la cuenca del Caribe
}

\section{Eduardo Gitli \\ egitli@racsa.co.cr}

\section{Randall Arce \\ marce@racsa.co.cr \\ Centro Internacional de Política Económica para el Desarrollo Sostenible (CINPE), Costa Rica}

El posible ingreso de China a la Organización Mundial del Comercio sin duda repercutirá fuertemente en muchas naciones. Aquí se analiza en particular el impacto que tendría sobre el comercio entre los Estados Unidos y los países de la cuenca del Caribe. Los problemas que ocasionó a estos últimos la adhesión de México al Tratado de Libre Comercio de América del Norte se podrían agravar ante el reacomodo de fuerzas que causaría esta nueva situación. La perspectiva de una considerable expansión de las exportaciones de productos textiles y vestuario desde China a los Estados Unidos agudizaría la competencia que deberían enfrentar los países de la cuenca y México en ese mercado. No obstante, la ampliación reciente de los beneficios comerciales otorgados por los Estados Unidos a la cuenca del Caribe, vigente a partir del 1 de octubre de 2000, da un plazo breve — unos cinco años — para que las exportaciones de estos países, sobre todo de prendas de vestir, intenten consolidarse. En el caso del calzado, la intensificación del comercio entre China y los Estados Unidos podría tener efectos adversos sobre las exportaciones de la República Dominicana al mercado estadounidense. En lo que toca a instrumentos de uso médico, las exportaciones de China competirían fuertemente con las realizadas por Costa Rica y la República Dominicana a ese mismo mercado. 


\section{I}

\section{Introducción}

La República Popular China ${ }^{1}$ se ha convertido en un actor importante en la economía mundial. Después de haber realizado grandes transformaciones en su estructura productiva y organizacional, este país ha logrado mantener importantes tasas de crecimiento durante los últimos años, que lo han llevado también a colocarse entre los principales exportadores e importadores mundiales. Sin embargo, en mucho su desempeño está condicionado por no formar parte de la Organización Mundial del Comercio (омc), lo que limita sus posibilidades de expansión comercial.

Por este motivo, China busca incorporarse a la OMC medio siglo después de haber dejado de formar parte de la entidad antecesora de esta organización: el Acuerdo General sobre Aranceles Aduaneros y Comer-

\section{II}

\section{Antecedentes}

China fue uno de los 23 países que originalmente firmaron el Acuerdo General sobre Aranceles Aduaneros y Comercio en 1948. Sin embargo, después de la revolución de 1949, el gobierno de Taiwán anunció que China dejaría de formar parte del GATT. En 1986, China notificó al GATT su interés en recuperar su status de parte contratante y sus intenciones de hacerlo. En marzo de 1987 se conformó un equipo de trabajo para analizar el status de China, cuya primera reunión se efectuó en octubre de ese mismo año (oMc, 2000).

China tiene alrededor de 1300 millones de habitantes y ha crecido rápidamente en los últimos años. En promedio, su producto interno bruto creció más de 11\% anual en 1990-1997, lo que lo colocó entre los países con mayor crecimiento económico durante los últimos años. Su inflación media en ese período fue inferior al 8\%, pero en 1998 y 1999 registró una variación de precios de $-0.8 \%$ y de $-1.4 \%$ (Banco Mun-

\footnotetext{
1 Este trabajo se refiere a la República Popular China, pero por razones de conveniencia nos referiremos a este país simplemente como China.
}

cio (GATT). Su objetivo es mejorar su inserción en el entorno internacional en lo que al comercio se refiere, para aprovechar así las ganancias derivadas del proceso de globalización. En este sentido, el acuerdo bilateral entre China y los Estados Unidos firmado en noviembre de 1999 dio un impulso importante a las negociaciones llevadas a cabo por China con el objetivo de ingresar a la organización que reemplazó al GATT.

Aún están por verse los alcances de dicho acuerdo bilateral en lo que se refiere al comercio entre los Estados Unidos y China. Sin embargo, es preciso evaluar cuáles podrían ser sus efectos sobre el intercambio entre los países de la cuenca del Caribe y los Estados Unidos. Tal es el objetivo primario de este artículo. dial, 1999; FMI, 2000b). Hacia 1996, un $71.2 \%$ del producto industrial bruto del país era generado por las empresas privadas, ${ }^{2}$ las que a su vez contabilizaban el 42.6\% del empleo urbano (Lin, Cai y Li, 1998, p. 422).

A pesar del bajo ingreso per cápita de China, su producto nacional bruto (PNB) total en términos de la paridad del poder de compra es cuatro veces el de Brasil y más de dos veces el de Alemania. Por lo tanto, es un fuerte candidato a comprar alimentos, bienes de capital y electrodomésticos básicos. Su actividad productiva de exportación está concentrada en una proporción reducida del territorio. Aproximadamente el $70 \%$ de la inversión extranjera directa (IED) que recibe se concentra en cinco provincias costeras ubicadas al este y sudeste del país: Guangdong, Jiangsu, Fujian, Shanghai y Shandong. ${ }^{3}$ De hecho, estas provincias son

\footnotetext{
${ }^{2}$ Este porcentaje debe interpretarse con precaución, porque incluye algunas empresas comunales, además de las netamente privadas.

3 Para los fines de este trabajo, se ha incluido en la inversión extranjera la proveniente de la región administrativa especial de Hong Kong y la provincia china de Taiwán, a las que en adelante nos referiremos como Hong Kong y Taiwán.
} 
consideradas parte muy importante del "milagro chino", pues han tenido tasas de crecimiento superiores al 20\% entre 1985 y 1989 (Mody y Wang, 1997, p. 294). Esto se debe en parte a la localización de las zonas empresariales especiales (ZEE), y al mismo tiempo refleja la concentración geográfica de las organizaciones a las que las autoridades chinas tienen permitido comerciar (Comisión de Comercio Internacional, 1999b, pp. 2-23). Las empresas ubicadas en esas zonas reciben incentivos importantes, como la exoneración de impuestos sobre los beneficios y de pago de aranceles para la importación de bienes de capital o materias primas que serán reprocesadas dentro de ellas. En este caso, las zEE son importantes receptoras de operaciones de escasa elaboración provenientes de Hong Kong y Taiwán, especialmente en productos de la confección (Bosworth y Ofer, 1995).

La IED tiene bastante importancia en la economía china. De hecho, en 1998 un 51.8\% de la que se dirigió a los países de Asia y el Pacífico se estableció en China ${ }^{4}$ (UnCTAD, 1999). Dentro de China la IED está fuertemente concentrada según su origen. En 1997 casi la mitad de la IED realizada provino de Hong Kong (cuadro 1). Le siguieron Japón (9.6\%), Taiwán (7.3\%), Estados Unidos (7.2\%) y Singapur (5.8\%) con contribuciones más moderadas. Esta concentración de la IED puede deberse a las restricciones a la entrada de capitales que impone China, las que no son aplicables a Hong Kong; esto podría significar que algunos de esos capitales son en realidad taiwaneses. Al mismo tiempo, un $62 \%$ de la inversión extranjera directa se dirige a las manufacturas (Comisión de Comercio Internacional, 1999b, pp. 2-14).

Los socios comerciales más importantes de China son Hong Kong (22.7\%), Japón (20.2\%) y los Estados Unidos (18.2\%), en lo que al destino de sus exportaciones se refiere (FMI, 2000a). Las manufacturas que hacen uso intensivo de trabajo, como la con-

\footnotetext{
${ }^{4}$ Estos datos no incluyen la inversión que se estableció en Japón. Si consideramos que Hong Kong es desde 1997 una región de régimen especial de China, entonces este porcentaje se eleva al 53.7\%.
}

CUADRO

\section{China: Inversión extranjera directa acumulada por país de origen, 1997 (Millones de dólares y porcentajes)}

\begin{tabular}{lrc}
\hline País de origen & Valor & Porcentaje \\
\hline Hong Kong & 20630 & 45.6 \\
Japón & 4330 & 9.6 \\
Taiwán & 3290 & 7.3 \\
Estados Unidos & 3240 & 7.2 \\
Singapur & 2610 & 5.8 \\
República de Corea & 2140 & 4.7 \\
Reino Unido & 1860 & 4.1 \\
Alemania & 990 & 2.2 \\
Macao & 390 & 0.9 \\
Canadá & 340 & 0.8 \\
Australia & 310 & 0.7 \\
Sub total & 40130 & 88.6 \\
Otros & 5148 & 11.4 \\
Total & 45278 & 100.0 \\
\hline
\end{tabular}

Fuente: Comisión de Comercio Internacional (1999b).

fección, el calzado, los juguetes, los juegos, el equipo deportivo y los productos de cuero, figuran entre sus principales productos de exportación. Lo anterior refleja el hecho de que, en comparación con otros países, China es rica en mano de obra y pobre en capital.

Con respecto a los proveedores de China, los más importantes son: Hong Kong (34.8\%), Japón (12.8\%), Taiwán (9.8\%), Estados Unidos (7.4\%) y la República de Corea $(7.1 \%)$. Los principales productos de importación son los aviones, la maquinaria eléctrica, los fertilizantes y la maquinaria no eléctrica ${ }^{5}$ (FMI, 2000a).

La composición del comercio de China ha cambiado fuertemente en los últimos 20 años, yendo de una estructura basada en productos primarios hacia una basada en las manufacturas. En 1997, el 85\% de las exportaciones chinas eran bienes manufacturados. ${ }^{6}$

\footnotetext{
${ }^{5}$ En realidad una parte de las importaciones y exportaciones de Hong Kong son redirigidas, por lo que esta estructura no es demasiado confiable.

${ }^{6}$ Estimación hecha por los autores, utilizando la base de datos de comercio mundial PC/TAS.
} 


\section{III}

\section{El proceso de negociaciones para el ingreso de China a la Organización Mundial del Comercio}

China es uno de los 30 países que actualmente negocia su incorporación a la OMC (ex GATT). El país está llevando a cabo reformas importantes y transformando su economía en una más basada en el mercado. Su proceso de admisión es negociado por un grupo de trabajo que integran miembros de la organización. Inicialmente (desde 1987), el grupo de trabajo adscrito al GATT analizó el régimen comercial chino de bienes. Pero a partir de 1995, el grupo vinculado con la recién creada OMC incluyó entre los temas de análisis el comercio de servicios, las nuevas reglas sobre medidas no arancelarias y las reglas sobre los derechos de propiedad intelectual.

Una parte muy importante del proceso de admisión de China a la OMC son las negociaciones bilaterales entre este país y los miembros de la organización interesados. Estos países miembros avanzan bilateralmente, negociando los requisitos impuestos al ingreso. Al final del proceso, China debe conseguir dos tercios de los votos de los países miembros para ser admitida en la organización. ${ }^{7}$ Por su parte, el grupo de trabajo está encargado de vigilar la evolución general de estas conversaciones bilaterales. ${ }^{8}$

En el gráfico 1 podemos apreciar cuáles son las etapas que faltan para que China pueda ingresar a la омc. Primero, tiene que terminar de negociar con los países que así se lo solicitaron, etapa en la cual tuvo problemas con la Unión Europea. Después de eso, debería consolidar todas sus negociaciones dentro del grupo de trabajo y cada país miembro deberá decidir si está de acuerdo con que China ingrese a la omc. Posteriormente, el Consejo General (formado por todos los países miembros de la organización) deberá aprobar o rechazar el conjunto de plazos y condiciones para la admisión de China. Generalmente el Consejo toma estas decisiones por consenso, pero de no ser eso posible, una mayoría de dos tercios puede aprobar la incorporación. Finalmente, China tiene que dar comienzo al proceso de aplicación de sus obligaciones y se vuelve miembro de la omc (GAO, 2000, p. 9).

\section{La apertura unilateral china}

En 1998, China informó de algunas de las concesiones que ha brindado durante los doce años transcurridos desde la presentación de la solicitud formal de reincorporación al GATT (hoy OMC). Algunas de ellas (омC, 2000) son las siguientes:

- China redujo los aranceles medios (no incluidos los productos agrícolas) de $42.7 \%$ en 1992 a $17 \%$ en 1998. Al tiempo, estaban previstas reducciones adicionales al 10\% para 2005.

- Redujo las medidas no arancelarias de 1247 en 1992 a menos de 400 en 1998. Además, existe un calendario para eliminar aquellas inconsistentes con las disposiciones de la OMC.

- Estuvo conforme con firmar el Acuerdo sobre Tecnología de la Información, que incluye la reducción a cero de los derechos arancelarios en una variedad de productos de este rubro.

- Sostuvo que no tenía regímenes de subsidios a las exportaciones de productos agrícolas.

- Afirmó que había progresado en las negociaciones sobre el comercio de servicios. Existían en ese momento 150 bancos extranjeros operando en China.

\footnotetext{
${ }^{7} \mathrm{Si}$ bien las negociaciones en esta etapa son bilaterales, al ingresar China a la OMC deberá extender automáticamente toda concesión bilateral al resto de los países sobre la base del principio de la nación más favorecida.
}

\footnotetext{
8 A julio de 2000, China había concluido negociaciones con 35 países miembros. El acuerdo con la Unión Europea se había retrasado debido a discrepancias en torno a la apertura de los sectores chinos relacionados con los servicios, tales como las telecomunicaciones, los servicios financieros y los seguros.
} 


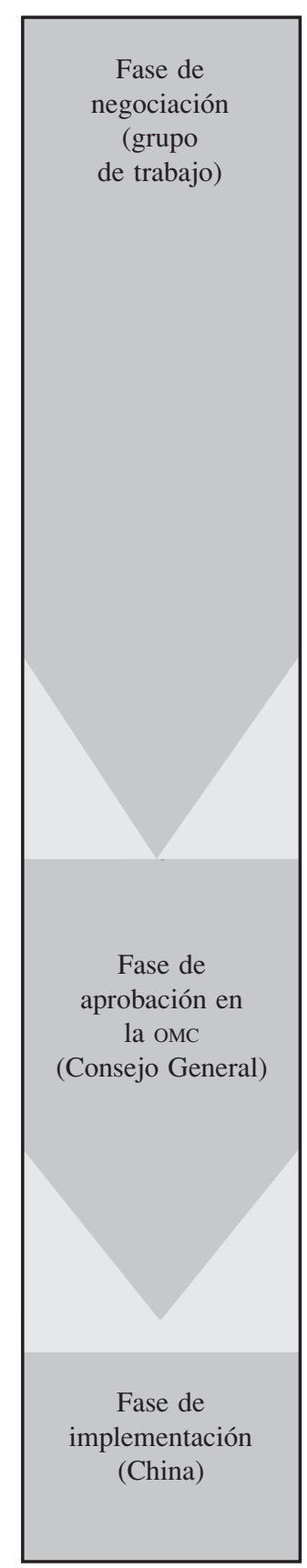

Fase de

(grupo

de trabajo)

Fase de aprobación en

la OMC (Consejo General)

Fuente: GAO (2000).
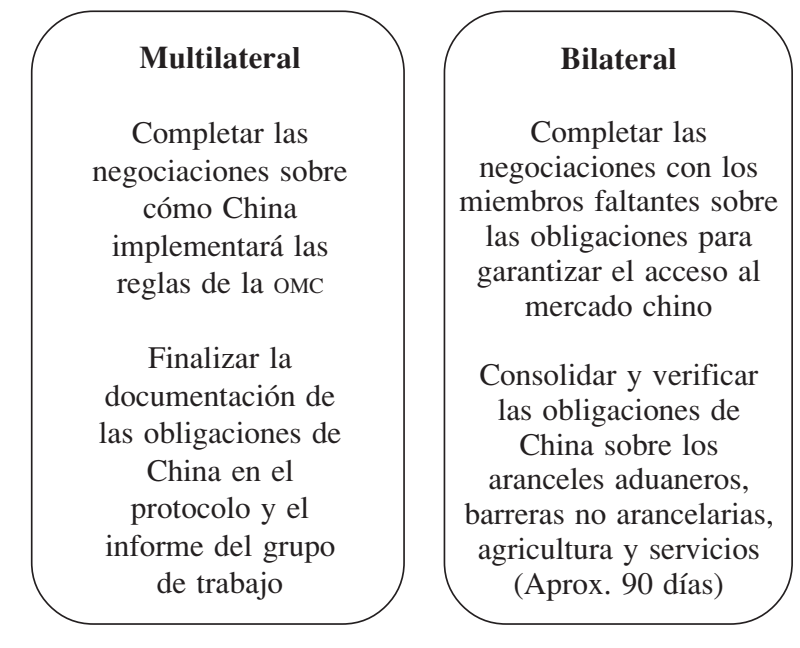

China y el grupo de trabajo alcanzan consenso

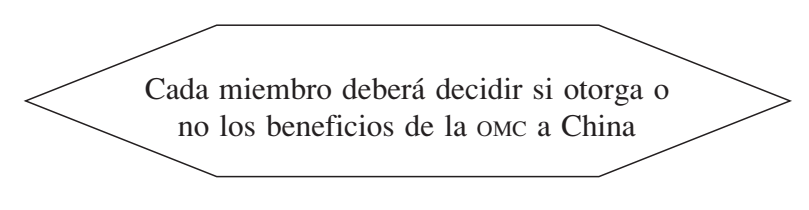

\section{Consejo General}

Aceptar o rechazar el "paquete" de ingreso de China

China completa todos los requerimientos internos para aceptar e implementar los acuerdos y notificar formalmente a la OMC
China se convierte en miembro de la $\mathrm{OMC}$ 


\section{Las relaciones China - Estados Unidos}

\section{Intercambio comercial entre estos dos países}

En lo que se refiere al comercio bilateral, China es un país importante para los Estados Unidos, dado que hacia 1997 un 7.2\% de las importaciones estadounidenses provenían de China, un incremento considerable desde el 5.4\% de 1993 (cuadro 2). En lo que respecta a las exportaciones de los Estados Unidos, las ventas a China se mantuvieron estables entre 1993 y 1997, representando un $1.9 \%$ del total. Esta cifra indica que Estados Unidos puede aspirar a expandir sustancialmente sus envíos a ese país. China ocupa el cuarto lugar entre los países de origen de las importaciones estadounidenses y el décimotercero entre los receptores de las exportaciones de los Estados Unidos.

Visto desde el ángulo de China, Estados Unidos es un muy importante socio comercial, hacia el cual en 1997 dirigió un $25.9 \%$ de sus exportaciones y al cual compró un $15.1 \%$ de sus importaciones. La situación fue bastante favorable para China, dado el balance comercial positivo a su favor de 49747 millones de dólares.

En el cuadro 3 se muestra la estructura del comercio realizado entre los Estados Unidos y China en 1998. Como se aprecia, las importaciones de los Estados Unidos se concentran en cuatro secciones: máquinas y aparatos, material eléctrico y sus partes (29.0\%); mercancías y productos diversos $(21.4 \%)$; calzado, sombrerería, flores artificiales $(13.1 \%)$, y materias tex-

CUADRO 2

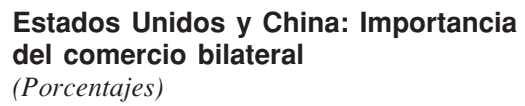

$1993 \quad 1997$

Importaciones de EE.UU. desde China respecto a las importaciones totales de EE.UU. $\quad 5.4 \quad 7.2$ Exportaciones de EE.UU. hacia China respecto a las exportaciones totales de EE.UU. $1.9 \quad 1.9$

Importaciones de China desde EE.UU. respecto a las importaciones totales de China $13.0 \quad 15.1$

Exportaciones de China hacia EE.UU. respecto a las exportaciones totales de China

$22.4 \quad 25.9$

Fuente: Departamento de Comercio de los Estados Unidos, Módulo para el análisis del crecimiento del comercio internacional (MAGIC) y Naciones Unidas (PC-TAS). tiles y sus manufacturas (10.1\%). Por su parte, las exportaciones estadounidenses a China se centran en tres secciones: máquinas y aparatos, material eléctrico y sus partes (31.9\%); material de transporte (26.6\%), y productos de las industrias químicas (11.5\%).

\section{El Acuerdo China - Estados Unidos ${ }^{9}$}

E1 15 de noviembre de 1999 Estados Unidos y China firmaron un acuerdo bilateral que preparó el terreno para que China pueda ingresar a la Organización Mundial del Comercio. Este acuerdo considera temas como el acceso de los productos estadounidenses al mercado chino, la posibilidad de realizar inversiones en servicios, el comercio y los derechos de distribución, entre otros.

Sin embargo, tal acuerdo no es un hecho aislado, sino que forma parte de un cambio general en la forma de relacionarse de los Estados Unidos con la nación asiática, derivada en parte de la importancia que ésta ha adquirido durante los últimos años. Cabe recordar que después de los trágicos eventos de la Plaza de Tiananmen las relaciones entre los dos países tuvieron un bajo perfil durante más de una década. Sin embargo, ya en 1996 el presidente Clinton anunciaba que la estabilización de las relaciones con China sería una prioridad durante su segunda administración, y en 1997 la primera cumbre entre los presidentes de ambos países fue una señal importante en torno a la normalización.

Los principales elementos contemplados en este acuerdo bilateral se enumeran a continuación.

\section{a) Provisiones generales}

$\mathrm{El}$ acuerdo incluye una serie de disposiciones que de hecho significan que el ingreso de China a la OMC estaría sujeto a medidas defensivas unilaterales por parte de los Estados Unidos en varios terrenos. En primer lugar, incluye un mecanismo especial de salvaguardia que permanecerá vigente 12 años después de dicho ingreso. Este mecanismo puede ser utilizado para con-

\footnotetext{
${ }^{9}$ La descripción de los principales elementos del Acuerdo ChinaEstados Unidos está basada en US-China Business Council (2000).
} 


\begin{tabular}{|c|c|c|c|c|}
\hline & Importaciones & Porcentaje & Exportaciones & Porcentaje \\
\hline XVI. Máquinas y aparatos, material eléctrico y sus partes & 20385.0 & 29.0 & 4472.8 & 31.9 \\
\hline XX. Mercancías y productos diversos & 15041.3 & 21.4 & 101.3 & 0.7 \\
\hline XII. Calzado, sombrerería, flores artificiales & 9230.4 & 13.1 & 33.2 & 0.2 \\
\hline XI. Materias textiles y sus manufacturas & 7114.9 & 10.1 & 267.4 & 1.9 \\
\hline XV. Metales comunes y manufacturas de estos metales & 3052.6 & 4.3 & 469.0 & 3.3 \\
\hline XVIII. Instrumentos y aparatos de óptica, fotografía, música & 2991.7 & 4.3 & 682.2 & 4.9 \\
\hline VII. Materias plásticas, caucho y sus manufacturas & 2388.2 & 3.4 & 445.0 & 3.2 \\
\hline VI. Productos de las industrias químicas & 1453.9 & 2.1 & 1613.6 & 11.5 \\
\hline XIII. Manufacturas de piedra, yeso, cemento, cerámica, vidrio & 1276.1 & 1.8 & 90.6 & 0.6 \\
\hline Subtotal & 65906.5 & 93.7 & 8341.7 & 59.4 \\
\hline Otros & 4473.4 & 6.30 & 5692.6 & 40.6 \\
\hline
\end{tabular}

Fuente: Elaboración propia a partir de datos del Departamento de Comercio de Estados Unidos, MAGIC.

a El Sistema Armonizado se divide en 21 secciones.

trolar rápidos incrementos de las importaciones desde China que causen o amenacen causar problemas en los Estados Unidos.

\section{b) Metodología antidumping}

Estados Unidos puede continuar aplicando una metodología para economías que no sean de mercado en los casos de antidumping relativos a importaciones desde China. Esta disposición, que permanecerá en vigencia por 15 años, después del ingreso de China a la OMC, permitirá a Estados Unidos tomar en consideración las características especiales de la economía china cuando identifique y cuantifique posibles beneficios provenientes de subsidios. Al mismo tiempo, China puede solicitar que Estados Unidos revise sectores específicos, o la economía china como un todo, para determinar si su orientación es de mercado y, por lo tanto, no está totalmente sujeta a la metodología especial de economía no orientada al mercado.

\section{c) Comercio y derechos de distribución}

Las empresas estadounidenses que operen en China podrán distribuir productos importados, así como productos que ellas elaboren en este país, lo cual proporcionaría una gran oportunidad para expandir las exportaciones a China. Anteriormente, las empresas podían distribuir sus productos únicamente cuando los producían directamente en China, y si los importaban, la distribución tenía que realizarse a través de empresas estatales creadas para este fin. Una de las razones por las cuales las empresas estadounidenses decidían instalar una planta de producción en China era la de poder vender a un mercado tan importante. Bajo las condiciones del acuerdo, las compañías estadounidenses podrán vender sus productos cualquiera sea el lugar donde los elaboren, lo que les permitirá incrementar sus exportaciones.

\section{d) Servicios}

El acuerdo establece que China proveerá acceso a su sector de comunicaciones así como a los de seguros, servicios financieros, servicios profesionales y servicios relacionados con la computación. En telecomunicaciones, después de la incorporación de China a la омC, los operadores extranjeros podrán tener una participación del $25 \%$ en las firmas de telecomunicación móvil, que se incrementará al $49 \%$ a partir del tercer año. En los servicios de Internet se permitirá el acceso al 30\% del servicio en las provincias de Beijing, Shanghai y Guangzhou, el que se incrementará al 50\% en dos años, cuando todas las restricciones geográficas hayan desaparecido. Si bien es cierto que China ha alcanzado cierta apertura en materia de servicios financieros, todavía la participación privada internacional en esta actividad es muy reducida. Al mismo tiempo, el hecho de que los mercados de capitales hayan crecido 
muy fuertemente en China durante los años noventa se convierte en un importante incentivo para que el gobierno estadounidense desee asegurarse el acceso a estos mercados (Naciones Unidas, 1999).

\section{e) Productos industriales}

Los aranceles industriales chinos se reducirían de un promedio general de un 24.6\% ad valorem en 1997 (mayor que el efectivo en la actualidad), a un promedio general de $9.4 \%$ en 2005 . Los aranceles sobre los productos industriales de especial interés para los Estados Unidos se reducirán a un promedio de $7.1 \%$ ad valorem y la mayor parte de esas reducciones arancelarias estarán en vigor para el año 2003. Los aranceles para automóviles bajarán aceleradamente desde los niveles actuales del $80-100 \%$ ad valorem al $25 \%$ en 2006, y su reducción mayor se verificará el primer año después de la incorporación de China a la OMC. Al respecto, China accedió a reducir estos aranceles a cambio de un plazo ligeramente más largo. ${ }^{10}$ También acordó eliminar todos los aranceles sobre bienes como computadoras, equipo de telecomunicaciones, semiconductores y otros productos de alta tecnología, siendo esto congruente con la firma del Acuerdo sobre Tecnología de la Información. Los aranceles para este tipo de productos pasarán de un promedio actual del $13.3 \%$ a 0 en el año 2005.

En madera y papel, los aranceles serán reducidos de sus niveles actuales de $12-18 \%$ para la madera y $15-25 \%$ para el papel a niveles que se hallarán generalmente entre 5 y $7.5 \%$. En el caso de los textiles, el acuerdo incluye un Protocolo sobre la base de los acuerdos textiles establecidos en 1997, el cual permite que las compañías y los trabajadores estadounidenses puedan responder ante el incremento de las importaciones de productos textiles y de la confección, utilizando una salvaguarda. Esta salvaguarda permanecerá en aplicación hasta el 31 de diciembre de 2008, es decir, cuatro años después de que deje de regir el Acuerdo sobre los Textiles y el Vestido de la omc (White House, 2000).

\section{f) Productos agrícolas}

China estuvo de acuerdo en permitir el comercio privado en productos agrícolas. Los aranceles de China sobre los productos estadounidenses prioritarios

\footnotetext{
10 Sin embargo, hay quejas en Estados Unidos de que este nivel arancelario acordado puede ser todavía muy alto y que seguiría restringiendo al sector exportador estadounidense (The Journal of Commerce, 2000a).
}

CUADRO 4

\section{China: Aranceles negociados} con los Estados Unidos

\begin{tabular}{lcc}
\hline $\begin{array}{l}\text { Productos prioritarios } \\
\text { estadounidenses }\end{array}$ & $\begin{array}{c}\text { Arancel vigente } \\
(\%)\end{array}$ & $\begin{array}{c}\text { Arancel del acuerdo } \\
(\%)\end{array}$ \\
\hline Uvas & 40 & 13 \\
Carne & 45 & 12 \\
Pollo y pavo & 20 & 10 \\
Pescado & 25.3 & 10.6 \\
Queso & 50 & 12 \\
Yogur & 50 & 10 \\
Helados & 45 & 19 \\
Carne de cerdo & 20 & 12 \\
Vino & 65 & 12 \\
Pollo & 20 & 10 \\
\hline
\end{tabular}

Fuente: US-China Business Council (2000)

serán reducidos de un promedio global del $31 \%$ ad valorem al $14 \%$ a más tardar en enero del 2004 . Además, el promedio arancelario chino para los productos agrícolas se reducirá de un $22 \%$ a un $17.5 \%$. Las condiciones arancelarias para algunos sectores específicos de interés para los Estados Unidos que fueron establecidas en el acuerdo figuran en el cuadro 4 .

También convino en eliminar los subsidios a las exportaciones, que eran una preocupación clave para los productores estadounidenses de arroz y algodón. Otros compromisos fueron los de eliminar las barreras sanitarias y fitosanitarias que no estén basadas en pruebas científicas, y otorgar el derecho de importar y distribuir productos en China sin necesidad de recurrir a los intermediarios comerciales del Estado. ${ }^{11}$

\section{La situación en Estados Unidos respecto al ingreso de China a la omc}

El sector sindical estadounidense se oponía al acuerdo firmado con China, manifestando que este país debería mejorar sus prácticas laborales antes de acceder a relaciones comerciales normales. Además, aducía que los bajos precios de los productos chinos harían que éstos inundaran el mercado estadounidense, trayendo como consecuencia la pérdida de empleos (The Journal of Commerce, 2000c).

\footnotetext{
11 Al respecto, es importante señalar que mientras Estados Unidos solicita a la Unión Europea, la omc y China la eliminación de subsidios agrícolas, internamente otorgó 6 billones y 9 billones de dólares a los agricultores en los dos últimos años (The Journal of Commerce, 2000c)
} 


\section{Recuadro 1 \\ ¿Qué se entiende por Relaciones Comerciales Normales y Permanentes?}

El status comercial de nación más favorecida (NMF) es lo que la legislación estadounidense denomina actualmente Relaciones Comerciales Normales y Permanentes (RCNP). El NMF es el instrumento mediante el cual todos los miembros de la Organización Mundial del Comercio se garantizan, entre ellos, una condición arancelaria normal y permanente, por lo que si China se vuelve parte de la omc debería serle otorgada esta condición por los países miembros de ella.

En este sentido, Estados Unidos debe aprobar la legislación correspondiente a RCNP para China, porque su legislación actual impide otorgársela, como consecuencia de la aplicación del Título IV de la Ley de Comercio de 1974; esto hace que actualmente las condiciones arancelarias para los bienes chinos tengan que ser renovadas cada año. De no ser aprobada la nueva condición para la nación asiática, Estados Unidos no disfrutaría de las concesiones más importantes que China ha hecho para convertirse en miembro de la omc, tales como la liberalización de los servicios financieros, las telecomunicaciones y la distribución. Por eso, para el gobierno estadounidense es importante la aprobación de un régimen de relaciones comerciales normales y permanentes con China.

Fuente: Lardy (2000).

El tema del respeto a los derechos humanos en China también estuvo presente como una fuente de confrontaciones. Algunos consideraban que Estados Unidos no debería firmar un acuerdo con China mientras no mejorara la situación de los derechos humanos en este país y se evitaran sus constantes violaciones (Public Citizen, 1999). Otros estimaban que había habido avances importantes y que se debía comprender que los cambios en este sentido son un proceso largo, así que este tema no debería obstaculizar la normalización de las relaciones entre los Estados Unidos y China (Bates, 1999). Al parecer estas consideraciones fueron tomadas en cuenta, pues la legislación finalmente aprobada establece la conformación de una comisión encargada de darle seguimiento a las condiciones de derechos humanos reinantes en China e informar al Congreso de sus resultados.

El tema ambiental pareciera no haber sido una prioridad dentro del acuerdo, y algunos opinan que los problemas ambientales chinos derivados del auge económico de los últimos años amenazan la frágil estructura social y política, y la infraestructura económica del país. Se ha insistido en que Estados Unidos aproveche esta oportunidad para cooperar con China en esta cuestión fundamental (Economy, 1999). Al respecto, el 19 de mayo de 2000 ambas naciones firmaron una declaración conjunta de cooperación ambiental, en la cual se hace hincapié en los temas relacionados con el cambio climático, el uso y transferencia de tecnologías limpias y la reducción de la emisión de gases que causan el efecto invernadero. Esta declaración se hizo en el marco del Foro sobre Ambiente y Desarrollo, que es un proceso de conversaciones realizadas entre Estados Unidos y China desde 1997. Sin embargo, no hay aún acciones concretas tendientes a materializar la cooperación estadounidense con China en este ámbito.

Además de las consideraciones comerciales del acuerdo, para Estados Unidos éste tiene un considerable peso geopolítico. La transformación de una sociedad cerrada y pobre (abierta solamente en espacios reducidos como las "zonas empresariales especiales") en un mercado consumidor de 1300 millones de habitantes tiene sentido económico, pero también tiene sentido estratégico distender el permanente dilema de asociación económica y confrontación político-militar entre China y Taiwán, o entre China y la India o con Rusia. Por este motivo seis ex Secretarios de Estado —desde Alexander Haig, Henry Kissinger y James Baker, hasta Warren Christopher- brindaron su apoyo a Clinton en una carta pública. ${ }^{12}$

\footnotetext{
${ }^{12}$ Es preciso recordar que durante el trámite de esta legislación el Congreso estadounidense discutía dos temas muy relacionados: i) el acuerdo entre Estados Unidos y China, mediante el cual la nación asiática cumplía con uno de sus compromisos para ingresar a la oмc, y ii) la aprobación de la legislación sobre relaciones comerciales normales con China, a partir de la cual no deberían de realizarse renovaciones anuales de los aranceles de entrada para los productos chinos. A septiembre de 2000, esta legislación estaba por aprobarse y solamente la detenían las exigencias de algunos legisladores de que se incluyera condicionantes relativos a la evolución del respeto a los derechos humanos en la nación asiática, así como al tráfico de armas.
} 


\section{V}

\section{Posibles efectos sobre la cuenca del Caribe}

El ingreso de China a la OMC y el reciente acuerdo bilateral firmado con los Estados Unidos podrían tener efectos adversos sobre la evolución del intercambio comercial entre los países de la cuenca del Caribe y los Estados Unidos, debido al incremento de la competencia china en ciertos sectores específicos. ${ }^{13}$

Como muestra el cuadro 5, resaltan cuatro sectores que por su importancia en las exportaciones de China a los Estados Unidos podrían incrementar la competencia con los productos de la cuenca del Caribe: i) la confección; ii) el calzado; iii) máquinas y aparatos, material eléctrico y sus partes, y iv) instrumentos y aparatos de óptica, fotografía y música. Mientras los artículos de confección son producidos en todos los países centroamericanos y la República Dominicana, el sector calzado es importante exclusivamente en este último país, donde en 1999 representó un 6.6\% de sus exportaciones totales a los Estados Unidos, mientras que para el resto de los países de la cuenca sólo significó menos del $0.7 \%$. A continuación analizaremos cada uno de estos sectores por separado.

\section{Productos de la confección}

China es para los Estados Unidos uno de los más importantes abastecedores de productos de la confección; sin embargo, como se aprecia en el cuadro 6, su participación de mercado en estos productos se redujo entre los años 1990 y 1998, pasando de un 13.9 a un $11.4 \%$. Esto se debe en gran parte a la existencia de cuotas restrictivas que limitan el aumento de estos bienes en el mercado estadounidense. Muchos de los productos de exportación chinos están sujetos a cuotas individuales, lo que ha reducido su crecimiento anual a 0.2 ó $0.5 \%$ (Comisión de Comercio Internacional, 1999a $)^{14}$.

Estados Unidos: Estructura de sus importaciones desde la República Popular China y la cuenca del Caribe, por secciones del Sistema Armonizadoa, 1998 (Millones de dólares y porcentajes)

\begin{tabular}{|c|c|c|c|c|}
\hline & China & Porcentaje & Cuenca del Caribe & Porcentaje \\
\hline XXI. Materias textiles y sus manufacturas & 7114.9 & 10.1 & 8390.9 & 50.2 \\
\hline II. Productos del reino vegetal & 295.3 & 0.4 & 1828.0 & 10.9 \\
\hline X. $\quad$ Productos minerales & 696.8 & 1.0 & 1291.0 & 7.7 \\
\hline XVI. Máquinas y aparatos, material eléctrico y sus partes & 20385.0 & 29.0 & 1159.5 & 6.9 \\
\hline IV. Productos de las industrias alimentarias, bebidas, tabaco & 299.7 & 0.4 & 1052.4 & 6.3 \\
\hline I. $\quad$ Animales vivos y productos del reino animal & 451.7 & 0.6 & 605.4 & 3.6 \\
\hline XI. Productos de las industrias químicas & 1453.9 & 2.1 & 535.9 & 3.2 \\
\hline XVIII. Instrumentos y aparatos de óptica, fotografía, música & 2991.7 & 4.3 & 420.8 & 2.5 \\
\hline XII. Calzado, sombrerería, flores artificiales & 9230.4 & 13.1 & 378.7 & 2.3 \\
\hline XIV. Perlas finas o cultivadas, metales preciosos & 399.5 & 0.6 & 315.4 & 1.9 \\
\hline Subtotal & 43318.9 & 61.6 & 15978.0 & 95.6 \\
\hline Otros & 27061.0 & 38.4 & 16722.0 & 4.4 \\
\hline Total & 70379.9 & 100 & 11940.6 & 100.0 \\
\hline
\end{tabular}

Fuente: Elaboración propia a partir de datos del Departamento de Comercio de los Estados Unidos, MAGIC.

a El Sistema Armonizado se divide en 21 secciones.

\footnotetext{
${ }^{13}$ Esto es diferente de analizar las oportunidades que se abren en el comercio entre los países de la cuenca del Caribe y China, lo que será objeto de otro trabajo.
}

\footnotetext{
${ }^{14}$ Contrario a lo que se cree, el costo del transporte marítimo no es importante como diferencial (Gitli y Arce, 2000a), pero el tiempo de entrega, la distancia por recorrer para resolver problemas específicos y el costo del transporte aéreo, pueden ser elementos mucho más importantes en contra de China.
} 
CUADRO 6

Algunos países: Participación de mercado en las importaciones de productos de la confección realizadas por los Estados Unidos, 1990-1999

\begin{tabular}{lrrrrrrrrrr}
\hline & 1990 & 1991 & 1992 & 1993 & 1994 & 1995 & 1996 & 1997 & 1998 & 1999 \\
\hline China & 13.9 & 14.5 & 15.8 & 17.4 & 15.3 & 12.9 & 13.2 & 13.4 & 11.4 & 11.1 \\
Cuenca del Caribe & 8.4 & 10.4 & 11.3 & 12.9 & 13.1 & 14.7 & 15.5 & 16.8 & 16.4 & 16.5 \\
México & 2.8 & 3.5 & 3.9 & 4.3 & 5.3 & 7.4 & 9.6 & 11.4 & 13.1 & 14.3 \\
\hline
\end{tabular}

Fuente: Elaboración propia a partir de datos del Departamento de Comercio de los Estados Unidos. Los productos de la confección corresponden a los capítulos 61 y 62 del Sistema Armonizado.

\section{a) Participación de mercado}

En este sentido, en febrero de 1997, Estados Unidos concluyó nuevos acuerdos con China en lo que se refiere al comercio de productos textiles y de la confección. Uno de ellos extendió la vigencia de las cuotas estadounidenses para los bienes chinos que no fuesen de seda por cuatro años, hasta el final de 2000. Esto redujo las cuotas para aquellos productos en los que China ha violado constantemente el límite mediante contrabandos por terceros países (triangulación realizada especialmente con Hong Kong y Singapur), aprovechando las cuotas subutilizadas por ellos; al mismo tiempo, se fortalecieron las normativas contra este tipo de comercio (recuadro 2).

Por su parte, los países de la cuenca del Caribe aumentaron durante los años noventa su participación en el mercado estadounidense, a partir del retroceso de los países asiáticos sujetos a cuotas, entre los cuales China es muy importante. A partir de 1994, México ha aprovechado las ventajas arancelarias otorgadas por los Estados Unidos en el marco del TLC de América del Norte, para incrementar sus exportaciones de productos de la confección hacia los Estados Unidos. Es un hecho que México es el país que ha aumentado con más rapidez sus exportaciones de estos bienes, por lo que se ha apoderado de la mayor proporción del mercado perdido por los países asiáticos; al mismo tiempo, en 1998, la cuenca del Caribe en su conjunto perdió participación de mercado, después de haber exhibido una tendencia ascendente durante la década. En el incremento de la participación de México a partir de 1995 también influyó su devaluación de finales de 1994, la que contribuyó a acrecentar las ventajas que este país había obtenido a través de dicho Tratado (Gitli y Arce, 2000a).

Una proporción importante de los productos de la cuenca del Caribe entra a los Estados Unidos bajo una condición especial, la de producción compartida. En el sector de la confección los países de la Cuenca representan un $83.7 \%$ del total de lo importado bajo este régimen (cuadro 7). Asimismo, del valor total que ingresa como producción compartida, un $63.9 \%$ corresponde a contenido de origen estadounidense; por lo tanto, los países de la cuenca no pagan aranceles sobre este porcentaje. ${ }^{15}$

Resalta la importante diferencia entre el componente estadounidense utilizado por los países latinoamericanos y el utilizado por todos los demás: para los primeros el porcentaje es como mínimo de $43.2 \%$ (en Guatemala), mientras que para los segundos es de apenas $16.5 \%$. Lo anterior refleja el hecho de que los países más alejados de los Estados Unidos, como los asiáticos, no tienen mucho incentivo para fabricar ropa bajo el régimen de producción compartida, por lo difícil que resultaría trasladar telas y otros insumos estadounidenses desde los Estados Unidos para iniciar la producción de los bienes.

Si China se incorporara a la OMC, en el 2005 la eliminación de las cuotas vigentes en el marco del Acuerdo sobre los Textiles y el Vestido permitiría incrementar de manera importante su participación en el mercado mundial, lo que afectaría fuertemente a otros abastecedores regionales de estos bienes. De hecho, según estimaciones del gobierno estadounidense, con la eliminación de las cuotas, China podría elevar su participación en el mercado mundial en más de seis puntos porcentuales en el 2005; esto le ayudaría a mantenerse como el principal abastecedor mundial de productos de la confección, para posteriormente estabilizar esa participación en alrededor de 37\% (Comisión de Comercio Internacional, 1999b).

\footnotetext{
15 Para el sector de la confección el ingresar bajo producción compartida significa que las telas han sido cortadas en Estados Unidos y enviadas a coser a la cuenca, pagando los derechos aduaneros solamente sobre el valor agregado en el extranjero. En cambio, China paga el arancel sobre la totalidad del producto. No está muy claro hasta dónde esto representa una ventaja hoy en día para los países de la cuenca, debido a que no sólo la mano de obra china es más barata, sino que también las telas lo son.
} 


\section{Recuadro 2 \\ El Acuerdo China - Unión Europea}

El 19 de mayo pasado, China y la Unión Europea llegaron a un acuerdo bilateral en torno a las preferencias arancelarias que le brindará el país asiático a la Unión Europea, con el objetivo de permitirle el acceso de esta última a China. A continuación presentamos algunos de los principales elementos de este acuerdo.

En lo que se refiere a los aranceles aduaneros para los 150 productos prioritarios de los países europeos, el arancel promedio se reducirá del 18.6 al $10.6 \%$.

Los aranceles para los cinco productos del calzado, que representan más del $70 \%$ de las exportaciones de calzado de la Unión Europea, se reducirán del 25 al $10 \%$.

En 52 productos relacionados con el sector de "maquinaria y aplicaciones", que representan el $26 \%$ del total de las exportaciones europeas, los aranceles se reducirán al 5-10\% desde los niveles superiores al 35\% vigentes actualmente. fueron:

Algunas de las concesiones obtenidas por la Unión Europea en lo que respecta a los productos agrícolas

\begin{tabular}{lcc}
\multicolumn{1}{c}{ Producto } & Arancel actual & Arancel acordado \\
\hline Mantequilla & $30 \%$ & $10 \%$ \\
Leche en polvo & $25 \%$ & $10 \%$ \\
Pastas & $25 \%$ & $15 \%$ \\
Vino & $65 \%$ & $14 \%$ \\
Mandarinas & $40 \%$ & $12 \%$
\end{tabular}

Igual que en el caso de los Estados Unidos, China se comprometió a firmar el acuerdo sobre medidas sanitarias y fitosanitarias en el marco de la omc.

En lo que respecta a telecomunicaciones, los operadores extranjeros podrán ser dueños del $25 \%$ del total de esta actividad. Este nivel se elevará al 35\% y $49 \%$ para los años primero y tercero después de haber entrado en vigencia el acuerdo. En el campo de los seguros, se autorizaron siete nuevas licencias para que compañías europeas provean este servicio. Los negocios de distribución al por menor ya no estarán sujetos a la restricción de alianza estratégica 50-50, así como tampoco a la restricción de $20000 \mathrm{~m}^{2}$ de tamaño máximo, o de no más de 30 puntos de venta.

Fuente: Unión Europea (2000).

Con respecto al mercado estadounidense, la incorporación de China a la OMC y la eliminación de las cuotas tendrían efectos considerables en la composición de los proveedores de las importaciones estadounidenses de productos de la confección (cuadro 8). Para estos productos, la participación de mercado de China se incrementaría en tres puntos porcentuales en el 2005, cuando las restricciones cuantitativas serían eliminadas. Por su parte, los países del Sur de Asia ${ }^{16}$ también se verían favorecidos por la eliminación de las cuotas: su participación se elevaría en aproximadamente cuatro puntos porcentuales hacia el 2005, y seguiría exhibiendo una tendencia ascendente en los años pos-

${ }^{16}$ India, Bangladesh, Nepal, Pakistán y Sri Lanka. teriores. El aumento en la participación de mercado de China y los países del Sur de Asia implicaría una reducción de aproximadamente cuatro puntos porcentuales en la participación de mercado de "todos los demás", entre los cuales indudablemente los países de la cuenca del Caribe se verían fuertemente afectados. ${ }^{17}$

Por otra parte, es preciso considerar que en virtud de la Ley de Comercio y Desarrollo aprobada en los Estados Unidos el año 2000 los países de la cuenca del Caribe disfrutan ahora de una ampliación de las preferencias arancelarias que les había brindado la

\footnotetext{
${ }^{17} \mathrm{Si}$ bien, como vimos en la sección IV, los Estados Unidos se reserva el derecho de aplicar las salvaguardias textiles hasta el año 2008, lo que arrojaría un poco más de incertidumbre para el período interino.
} 
Estados Unidos: Importaciones de productos de la confección que ingresan como producción compartida y contenido estadounidense de ellas, 1997

(Millones de dólares)

\begin{tabular}{|c|c|c|c|c|c|}
\hline & Total & $\begin{array}{l}\text { Producción } \\
\text { compartida }\end{array}$ & $\begin{array}{l}\text { Porcentaje } \\
\text { del total }\end{array}$ & $\begin{array}{c}\text { Contenido } \\
\text { estadounidense }\end{array}$ & $\begin{array}{l}\text { Porcentaje de producción } \\
\text { compartida }\end{array}$ \\
\hline México & 6586 & 5187 & 78.8 & 3368 & 64.9 \\
\hline Rep. Dominicana & 2349 & 2154 & 91.7 & 1358 & 63.0 \\
\hline Honduras & 1875 & 1586 & 84.6 & 1130 & 71.2 \\
\hline El Salvador & 1170 & 1006 & 86.0 & 580 & 57.7 \\
\hline Costa Rica & 827 & 791 & 95.7 & 524 & 66.2 \\
\hline Guatemala & 1150 & 706 & 61.4 & 305 & 43.2 \\
\hline Haití & 225 & 211 & 93.8 & 155 & 73.5 \\
\hline Colombia & 364 & 253 & 69.5 & 148 & 58.5 \\
\hline Nicaragua & 232 & 67 & 29.9 & 47 & 70.1 \\
\hline Los demás & 38374 & 599 & 1.6 & 99 & 16.5 \\
\hline Total & 53574 & 12939 & 24.2 & 8024 & 62.0 \\
\hline Cuenca del Caribe & 8307 & 6949 & 83.7 & 4438 & 63.9 \\
\hline
\end{tabular}

Fuente: Comisión de Comercio Internacional (1999b).

CUADRO 8

Países abastecedores de productos de la confección: Posibles pérdidas y ganancias de participación en el mercado estadounidense como resultado del ingreso de China a la омc y la eliminación de las cuotas

\begin{tabular}{lll}
\hline & Mercado mundial & Estados Unidos \\
\hline China & Aumento de más de 6\% & Aumento de un 3\% \\
México y Canadá & Ligera reducción & Pérdida de 2\% \\
Todos los demás & Pérdida de un 3\% & Pérdida de un 4\% \\
\hline
\end{tabular}

Fuente: Comisión de Comercio Internacional (1999b).

a Dentro de "todos los demás" se incluye a los países de la cuenca del Caribe, Brasil, los países de la Unión Europea y demás pequeños abastecedores. El estudio de la Comisión de Comercio Internacional no especifica por separado el impacto sobre los países de la cuenca en ningún caso, por lo que estos resultados corresponden a estimaciones de los autores.

Iniciativa de la Cuenca del Caribe (ICC). Estimamos que esta legislación, vigente a partir del 1 de octubre del 2000 , sin duda dará un nuevo impulso a la producción en los países de la cuenca y suavizará el efecto que tendrá sobre ellos la eliminación de las cuotas chinas. Así, del grupo de "todos los demás" la cuenca será la única subregión que no se verá perjudicada. ${ }^{18}$

${ }^{18}$ Véase una definición de "todos los demás" en la nota al pie del cuadro 8 .
Cabe destacar que el gobierno estadounidense también prevé una ligera pérdida en la participación de mercado de México a partir del 2005, como resultado de la eliminación de las cuotas para los productos de la confección. Sin embargo, este país se vería menos afectado debido a las preferencias con que cuenta en el marco del TLC de América del Norte.

\section{b) Los precios relativos y la competencia}

A continuación examinaremos los precios relativos con los que China abastece al mercado estadounidense, en comparación con los precios de los bienes provenientes de la cuenca del Caribe. Para hacerlo tomaremos el caso de los tres principales productos de la confección exportados por los países de la cuenca a Estados Unidos en 1998: pantalones de hombre, $T$-shirts de hombre y camisas de algodón de hombre. ${ }^{19}$ Como podemos apreciar en el cuadro 9, en estos productos China está abasteciendo el mercado estadounidense con precios bastante parecidos a los de los países de la cuenca, por lo que parece que, al menos en este caso, no estaría compitiendo en virtud de precios más bajos. Esto podría indicar que el principal factor de diferenciación después del ingreso de China a la OMC estaría en la eliminación de las cuotas.

${ }^{19}$ Estos productos representan un 3.7, 2.6 y $2.4 \%$, respectivamente, de las importaciones totales realizadas por los Estados Unidos desde los países de la Cuenca del Caribe y corresponden a las clasificaciones arancelarias 6203424015, 6109100012 y 6105100010 del Sistema Armonizado. 


\section{Recuadro 3 \\ La AMPlación de PReferencias para los países de la cuenca del Caribe POR PARTE DE LOS ESTADOS UNIDOS}

La Ley de Comercio y Desarrollo de 2000, de los Estados Unidos, amplió las preferencias arancelarias de que disfrutan los países de la cuenca del Caribe en el marco de la Iniciativa de la cuenca del Caribe de 1984.

Para el calzado, ${ }^{a}$ atún, petróleo y derivados, relojes, y los productos de cuero ("planos", como billeteras) ${ }^{\mathrm{b}}$ el arancel será el mismo que el de México, siempre que cumplan con las normas de origen del Tratado de Libre Comercio de América del Norte.

Los productos textiles y de vestuario quedan sujetos a un régimen especial, que contempla que para los siguientes productos habrá acceso libre de cuotas y aranceles: ${ }^{c}$

1. Productos de la confección elaborados a partir de tela e hilo estadounidenses, cortados en Estados Unidos (producción compartida o maquila), permitiéndose que los mismos hayan sufrido una serie de operaciones adicionales de lavado y procesamiento. Se posibilita también el corte de la tela estadounidense en la región, aunque en estos casos pareciera que no se permiten procesos posteriores al ensamblado.

2. Ciertos productos tejidos (knitted) en un país beneficiario con hilo elaborado en Estados Unidos (con la excepción de las medias catalogadas en la partida 6115 del Sistema Armonizado), y productos de la confección tejidos (knitted), cortados y completamente ensamblados en uno o más países beneficiarios, a partir de tela producida en la región utilizando hilo estadounidense. Esta concesión queda sujeta al límite inicial anual de 250 millones de metros cuadrados equivalentes de tela, que crecerá un $16 \%$ cada año hasta el 2004, momento a partir del cual el crecimiento de la cuota se establecerá por ley. En este caso pareciera que no se permiten procesos posteriores a la confección, porque esta opción no está claramente definida en la legislación.

3. T-shirts, diferentes a las de ropa interior, clasificadas como camisetas de punto, de algodón (61091000 del Sistema Armonizado) y camisetas de punto de las demás fibras textiles (61099010), elaboradas en uno o más países beneficiarios a partir de tela producida en uno o más países de la región, utilizando hilo hecho en Estados Unidos. Para este caso se establece un techo de 4.2 millones de docenas de camisetas confeccionadas con tela originaria, con un incremento anual de este límite del $16 \%$ hasta el 2004, cuando el crecimiento se establecerá por medio de una ley.

4. Cualquier producto de la confección clasificado bajo la subpartida 621210 (sostenes, brasieres), si el artículo es cortado y cosido, o ensamblado en los Estados Unidos, o en alguno de los países beneficiarios. Estos productos serán elegibles para el tratamiento preferencial, si incluyen como mínimo un $75 \%$ de tela estadounidense.

5. Aquellos productos ensamblados a partir de fibras, hilo o tela, no disponibles en cantidades comerciales en la región (países del TLC de América del Norte). Los productos elaborados a mano o productos folclóricos y el equipaje textil.

Por último, aquellos productos agrícolas especialmente sensibles, como el azúcar, ${ }^{\mathrm{d}}$ la carne, los jugos congelados, el tabaco y los estuches de joyas, que estaban sujetos a cuotas y luego fueron arancelizados, no sufren ningún cambio en la nueva legislación. Por lo tanto, en ellos no hay paridad con el TLC de América del Norte.

Fuente: Gitli y Arce (2000b).

a Desde 1990, si el calzado era maquilado, entraba libre de aranceles.

b Los productos planos quedaron desde 1990 sujetos a aranceles reducidos.

c En ciertos casos, como los señalados en los puntos 2 y 3, los productos están sujetos a cuotas.

d El acceso al mercado del azúcar para los países de la ICC está sujeto a cuota, pero exento de impuesto. 
CUADRO 9

\section{Países de la cuenca del Caribe y otros: Precios relativos de los principales productos de la confección importados por los Estados Unidos ${ }^{a-b}$ \\ (Promedio 1995-1998)}

\begin{tabular}{lrrr}
\hline País & $\begin{array}{c}\text { Pantalones } \\
\text { de hombre }\end{array}$ & $\begin{array}{c}\text { T-shirts } \\
\text { de hombre }\end{array}$ & $\begin{array}{c}\text { Camisas de } \\
\text { algodón de hombre }\end{array}$ \\
\hline China & 0.97 & 1.00 & 1.42 \\
Costa Rica & 0.95 & - & - \\
El Salvador & - & 0.78 & 0.64 \\
Guatemala & - & - & 0.81 \\
Hong Kong & 1.14 & 2.85 & 1.70 \\
Honduras & 1.00 & 0.88 & 0.77 \\
Jamaica & - & 0.91 & - \\
México & 0.98 & 1.01 & 0.77 \\
Rep. Dominicana & 1.00 & 0.80 & 0.86 \\
\hline
\end{tabular}

Fuente: Departamento de Comercio de los Estados Unidos, MAGIC.

a El hecho de que para algunos países de la cuenca del Caribe no se indiquen datos sobre algún producto no implica que este país no lo exporte, sino simplemente que no es uno de los primeros tres abastecedores de la región de este producto.

b Es muy probable que las importaciones realizadas por los Estados Unidos desde Hong Kong provengan realmente de China, por lo que este dato debe de tomarse con cuidado.

Sin embargo, hoy en día China no sólo es uno de los mayores proveedores mundiales de vestuario de menor precio, sino que también se está convirtiendo en un productor de bajos costos para confecciones de gran calidad y valor, lo que tal vez se deba a las cuotas impuestas por Estados Unidos para evitar la importación de productos de baja calidad. Esta transición hacia productos de mayor valor se refleja en el traslado de la producción de este tipo de bienes desde Hong Kong hacia China, que ha llevado a que se reduzcan los empleados de la industria de la confección en Hong Kong de 128 mil a 45 mil entre 1993 y 1998 (Comisión de Comercio Internacional, 1999b, sección 8, p. 6).

En este sentido, al aprobar la legislación sobre extensión de preferencias para los países de la cuenca del Caribe, lo que está promoviendo Estados Unidos es su propia producción interna. Lo anterior se debe a que la actividad de la cuenca está fuertemente centrada en el régimen de producción compartida, en la cual el 64\% del total de la vestimenta exportada por estos países corresponde a contenido estadounidense. Por lo tanto, la legislación aprobada fortalecerá el uso de hilo y tela estadounidenses en los países de la cuenca, de manera que el crecimiento futuro de las industrias textiles y de vestuario en estos países le permitirá a los Estados Unidos mejorar la desfavorable evolución de su industria textil interna, en la cual el empleo se re- dujo de 675 mil a 596 mil personas entre 1993 y 1998 (Comisión de Comercio Internacional, 1999b, sección 8 , p. 2). Los encadenamientos productivos derivados de la utilización intensiva de materia prima estadounidense son grandes, por lo que un incremento en la participación de mercado de la cuenca beneficiaría a la industria textil estadounidense.

La maraña de conflictos de intereses entre productores textiles, de la confección y distribuidores es sumamente difícil de desentrañar. El gráfico 2 resume la estructura e interrelaciones de estos grupos, así como sus enfoques a veces contradictorios. Los distribuidores tienden a requerir "paquetes completos" (Arias, 1999; Zúñiga, 1999; Gereffi, 2000). Si esto es así, a ellos (que muchas veces son también productores subcontratantes de ropa) no les interesa demasiado la procedencia de las telas, sino solamente su calidad y especificaciones. Por lo tanto, están dispuestos a entrar en negociaciones con quien sea (China, la ICC, etc.). En cambio, los productores de textiles estadounidenses están interesados en expandir el campo y las ventajas de la producción compartida como forma de ampliar el mercado para sus telas.

Sobre este punto Gereffi (2000) analizó la reestructuración del sector de la confección en Estados Unidos y llegó a la conclusión de que los productores establecidos tanto en México como en Asia apuntan a producir el "paquete completo". En el caso mexicano esta tendencia se explica por las posibilidades de integración productiva que le brinda el TLC de América del Norte, mientras que en el caso de Asia se debería a los fuertes encadenamientos existentes entre los productores asiáticos. Al respecto, $\mathrm{Ng}$ y Yeats (1999) encuentran que el intercambio de componentes e insumos entre los países asiáticos es mucho mayor de lo que podría pensarse. Por ejemplo, del total de las importaciones de este tipo de productos realizadas por dichos países en 1996, un 58.5\% correspondió a comercio intrarregional, lo que da una idea de la importancia de la "producción compartida" que estaría realizándose entre los países de Asia. ${ }^{20}$

China tiene todas las posibilidades de competir en el mercado internacional de productos de la confección, sobre la base de costos salariales bajos. Sus salarios solamente representan un $17 \%$ de los de Costa Rica,

\footnotetext{
${ }^{20}$ En este punto consideramos la "producción compartida" no como una clasificación aduanera, sino como una división del trabajo, por la cual cada país ejecuta diferentes fases del proceso productivo, según la mano de obra y el nivel de conocimiento de que dispone.
} 

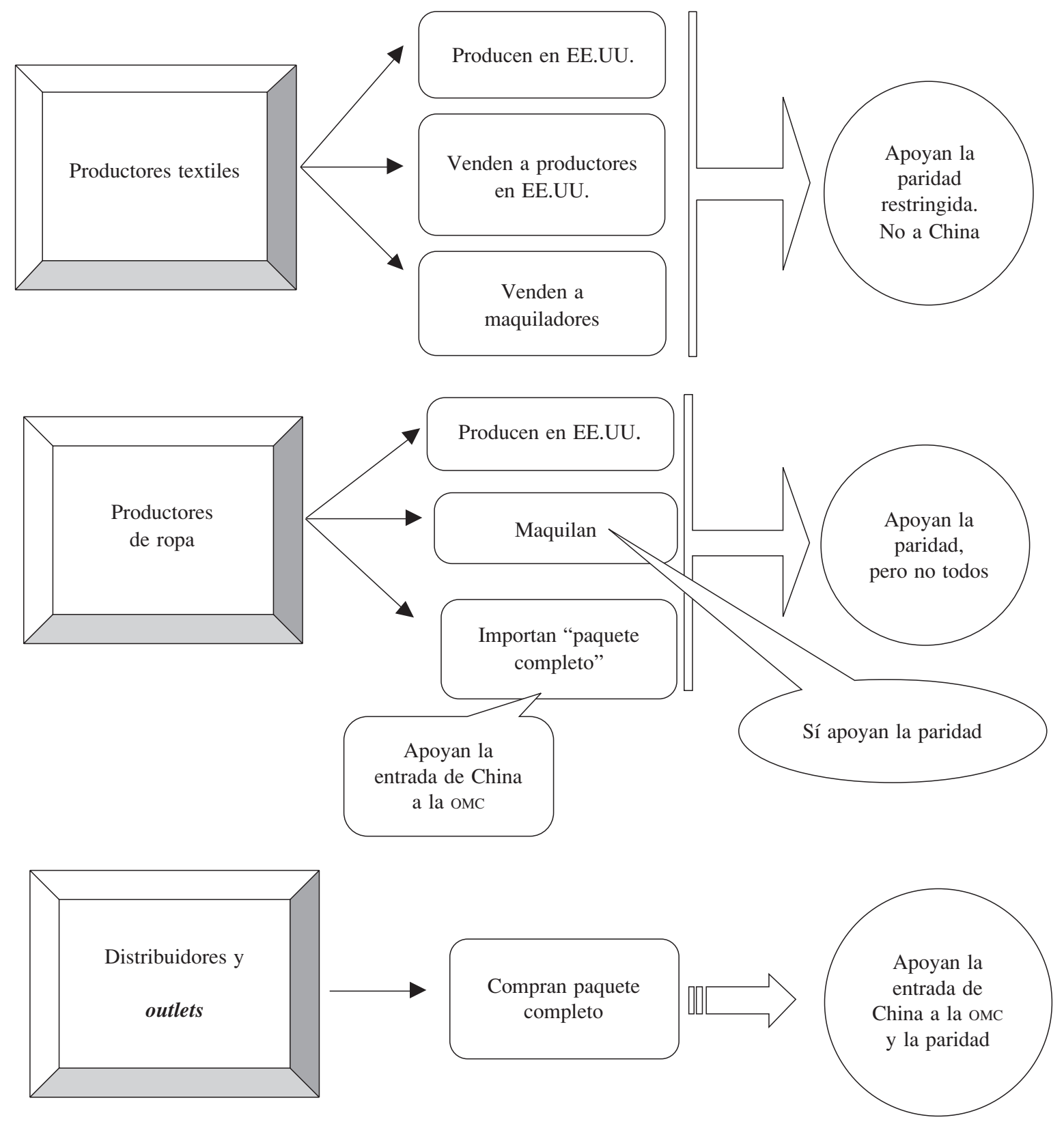
CUADRO 10

Algunos países: Costos laborales en la industria de la confección ${ }^{\mathrm{a}}$

(Dólares por hora)

\begin{tabular}{lrr}
\hline & 1996 & 1998 \\
\hline Estados Unidos & 9.56 & 10.12 \\
Hong Kong & 4.51 & 5.20 \\
Corea del Sur & 4.18 & 2.69 \\
Costa Rica & 2.38 & 2.52 \\
República Dominicana & - & 1.49 \\
México & 1.08 & 1.51 \\
Guatemala & 1.31 & 1.28 \\
Honduras & - & 1.05 \\
China & 0.28 & 0.43 \\
India & 0.36 & 0.39 \\
Bangladesh & 0.31 & 0.30 \\
Indonesia & 0.34 & 0.16 \\
\hline
\end{tabular}

Fuente: Comisión de Comercio Internacional (1999b, pp. 8-7) para los datos de 1996 y 1998; Gitli (1997) para los datos de la República Dominicana y Honduras, que corresponden a 1997.

a Los costos laborales incluyen las cargas sociales.

un $28.5 \%$ de los de México y un $33.6 \%$ de los de Guatemala, lo que hace que los precios finales de sus productos puedan ser bastante inferiores a los ofrecidos por los países de la cuenca (cuadro 10).

De las empresas de la confección ubicadas en China, en 1995 un $42 \%$ era de propiedad extranjera, casi un $40 \%$ correspondía a empresas comunitarias, ${ }^{21}$ un $7 \%$ a empresas privadas y solamente un $6 \%$ a empresas estatales. Además, la producción para exportación depende considerablemente de telas importadas de Hong Kong, Italia, la República de Corea, Taiwán y Japón, entre otros. Aproximadamente un 55\% de los productos de la confección es de tela importada (Comisión de Comercio Internacional, 1999b, sección 8, p. 5).

Como hemos visto, la suma del posible ingreso de China a la омc y la apertura de las cuotas para productos textiles en el año 2005 auguran una situación de gran crisis para los países de la cuenca del Caribe, los que tienen que asumir con seriedad el reto. Las decisiones de inversión que permitirán ampliar las ventajas competitivas deberán tomarse en este plazo.

\section{Calzado}

El calzado (capítulo 64 del Sistema Armonizado) podría ser otro tipo de bien en el que se incrementaría la

${ }^{21}$ Las empresas comunitarias corresponden a las denominadas township enterprises. competencia china con los países de la cuenca del Caribe. Como vimos anteriormente en el cuadro 5, un $13.1 \%$ de las importaciones realizadas por los Estados Unidos desde China corresponde a "Calzado, sombrerería y flores artificiales", la tercera sección en importancia en el comercio entre ambos países. En la cuenca del Caribe, como lo señalamos antes, el calzado es producido básicamente por la República Dominicana, de modo que el análisis posterior lo centraremos exclusivamente en este país.

Cabe aquí aclarar que el calzado está: i) excluido de las preferencias arancelarias del Sistema Generalizado de Preferencias; ii) semiexcluido de la Iniciativa de la cuenca del Caribe (si un país de la cuenca fabrica calzado bajo la modalidad de producción compartida, este bien estará libre de impuestos al momento de ingresar a los Estados Unidos), y iii) incluido en la ICC a partir de la nueva ley de 2000.

La República Dominicana efectúa un $34.2 \%$ de sus exportaciones de calzado bajo la modalidad de producción compartida, y de este rubro, un $66.5 \%$ corresponde a contenido estadounidense, por lo que se está beneficiando del ingreso exonerado de parte de los impuestos sobre estos productos a los Estados Unidos. En este sentido tiene una ventaja frente a China, país que si bien es cierto podría aprovechar los beneficios de la producción compartida, no lo hace por la existencia en el Este asiático de una estructura más eslabonada de la producción, con lo cual el abastecimiento de insumos se produce regionalmente.

Examinaremos ahora dos de los principales productos de exportación desde la República Dominicana, para determinar si existe o no competencia por parte de China y bajo qué condiciones de precio. Con este fin, analizaremos el primer y segundo productos de exportación desde la República Dominicana hacia los Estados Unidos dentro de la categoría de calzado: i) cortes separados y sus partes, excepto contrafuertes y punteras duras (6406106500), y ii) calzado (no deportivo) con suela de caucho, plástico, o de cuero natural o regenerado y parte superior de materias textiles (6404193515).

El primer producto - "cortes separados y sus partes, excepto contrafuertes y punteras duras"- representa un 4\% del total exportado a los Estados Unidos por la República Dominicana, por lo que es muy importante dentro de la estructura exportadora de este último país, cuya participación en el mercado estadounidense pasó de 47.3 a $60.5 \%$ entre 1990 y 1998, aunque alcanzó su máximo en 1994 (63.3\%) y luego comenzó a disminuir ligeramente. Por su parte, México 
ha aumentado su participación en ese mismo mercado, especialmente desde 1995, lo que podría deberse a los incentivos para invertir en este país derivados del TLC de América del Norte y, en alguna medida, de la devaluación mexicana de finales de $1994 .{ }^{22}$ China también incrementó de manera considerable su participación en el mercado estadounidense entre 1990 y 1998, pasando de un $0.5 \%$ a un $7.7 \%$. Sin embargo, ésta alcanzó su nivel más alto (10\%) en 1995 y luego empezó a disminuir.

Ahora bien, si analizamos la estructura de los precios relativos de cada uno de los principales países abastecedores de este bien, ${ }^{23}$ observamos lo siguiente: La República Dominicana provee este producto a precios $27 \%$ más altos que el promedio de los abastecedores, en tanto que México lo hace a precios un $4 \%$ más bajos que ese promedio. China vende a precios que son mucho más bajos aun que los mexicanos, y en promedio un 54\% más bajos que el promedio de precios de todos los abastecedores (cuadro 11).

Analicemos ahora el segundo producto de exportación desde la República Dominicana. Este producto es el "Calzado (no deportivo) con suela de caucho,

CUADRO 11

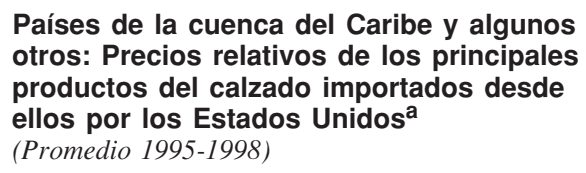

Países de la cuenca del Caribe y algunos otros: Precios relativos de los principales productos del calzado importados desde ellos por los Estados Unidos ${ }^{a}$ (Promedio 1995-1998)

\begin{tabular}{lcc}
\hline & $\begin{array}{c}\text { Cortes separados } \\
\text { y sus partes }\end{array}$ & $\begin{array}{c}\text { Calzado } \\
\text { (no deportivo) }\end{array}$ \\
\hline República Dominicana & 1.27 & 2.01 \\
China & 0.46 & 0.72 \\
México & 0.96 & 0.92 \\
Canadá & - & 1.54 \\
Honduras & 0.95 & - \\
India & 1.05 & - \\
Costa Rica & 1.59 & - \\
Argentina & 1.49 & - \\
\hline
\end{tabular}

Fuente: Departamento de Comercio de los Estados Unidos, MAGIC.

a Para algunos países no aparece el precio relativo de un producto, no necesariamente porque no lo vendan, sino porque no son competidores importantes con ese bien en las importaciones de los Estados Unidos.

${ }^{22}$ Además, un $8 \%$ del valor de las importaciones de calzado desde México corresponde a insumos estadounidenses (Comisión de Comercio Internacional, 1999c).

${ }^{23}$ Los precios relativos se refieren al precio de importación desde cada país en relación al precio de importación promedio desde todos los países. plástico, o de cuero natural o regenerado, y parte superior de materias textiles", y representa un $0.5 \%$ de las exportaciones totales a los Estados Unidos de la República Dominicana. Este último país incrementó de manera considerable su participación de mercado entre 1990 y 1998 , de 0 a $37.1 \%$. Su principal competidor, China, elevó la suya de $14.2 \%$ en 1990 a $35.5 \%$ en 1998. Por su parte, México, que era el principal abastecedor en 1990 (82\%), redujo significativamente su participación, que llegó a sólo $18 \%$ del total en 1998.

$\mathrm{Al}$ observar los precios relativos vemos reproducida, en este caso, la misma situación que en el producto anterior: la República Dominicana abasteció con precios relativos más elevados que el promedio (aproximadamente 60\% más altos en 1996-1998 y $100 \%$ en 1995-1998), mientras que China lo hizo con precios relativos 28\% más bajos en 1995-1998.

En este panorama, si el acuerdo suscrito estimula a los Estados Unidos a importar tal bien desde China, este último país podría competir en el mercado estadounidense con precios bastante más bajos que los de los países de la cuenca del Caribe y México, cuya competitividad en ese mercado podría verse afectada. Esto sucedería, porque se le estaría asegurando a China el arancel de nación más favorecida, lo que es casi tan importante como una reducción arancelaria, ya que da estabilidad al intercambio comercial que se realice con ese país.

\section{Otros instrumentos de uso médico, quirúrgico dental o veterinario ${ }^{24}$}

El cuarto producto de importación de los Estados Unidos desde la cuenca del Caribe lo constituyen "Otros instrumentos de uso médico, quirúrgico, dental o veterinario". Este rubro representó un 2.8\% de las importaciones totales realizadas por los Estados Unidos desde la cuenca en 1998, siendo los principales proveedores la República Dominicana y Costa Rica, con un 30.3 y un $5.5 \%$ de participación de mercado, respectivamente. México también abastece al mercado estadounidense en casi un $30 \%$. China, por su parte, proporcionó sólo $0.2 \%$ de las importaciones estadounidenses de estos productos, por lo que no parece significar una competencia muy importante para los países de la cuenca.

\footnotetext{
${ }^{24}$ Este producto se clasifica como el 9018908000 en el Sistema Armonizado.
} 


\section{Partes 0 accesorios de máquinas automáticas para el procesamiento de datos ${ }^{25}$}

Este producto ocupa el sexto lugar en las importaciones realizadas por los Estados Unidos desde los países de la cuenca del Caribe, y representó un 2.6\% del total importado desde estos últimos en 1998. El país de la cuenca que lo está proveyendo es Costa Rica, a partir de la creación de INTEL en 1997; su participación

\section{VI}

\section{Conclusiones}

El ingreso de China a la OMC generará grandes cambios en las relaciones comerciales recíprocas existentes entre ese país y los Estados Unidos, pero también afectará la evolución del intercambio que realizan ambos países con otros socios comerciales.

Uno de los mayores aumentos en las exportaciones de China hacia los Estados Unidos podría darse en el sector de los textiles y el vestido. Hasta el momento, este comercio está restringido por la existencia de cuotas, pero a partir de 2005 China podrá proporcionar crecientemente al mercado estadounidense productos más baratos, lo que no sólo perjudicará a la industria textil y del vestido estadounidense, sino que también incrementará la competencia que enfrentarán los países de la cuenca del Caribe y México, que son importantes abastecedores de productos de la confección. De hecho, el gobierno estadounidense prevé que China elevará su participación en el mercado estadounidense de productos de la confección en aproximadamente tres puntos porcentuales.

Lo anterior podría acarrear serios problemas a las economías de la cuenca, las cuales ya han visto reducirse el ritmo de crecimiento de sus exportaciones de textiles como resultado del TLC de América del Norte y de la devaluación mexicana de diciembre de 1994. No obstante, la reciente aprobación de la legislación que amplía las preferencias arancelarias de que disfruta la cuenca del Caribe en el marco de la ICC altera doblemente las reglas del juego, al favorecer a los países de la cuenca, y significa problemas para el resto de los exportadores de prendas de vestir.

${ }^{25}$ Este producto se clasifica como el 8473301000 en el Sistema Armonizado. en el mercado al año siguiente fue de $2.2 \%$. México también vende este tipo de productos a los Estados Unidos, y en 1998 contribuyó con un 7.9\% del total de compras estadounidenses de esta índole. Por su parte, China también participó ese mismo año en el mercado estadounidense con un 5.0\%, convirtiéndose así en un importante competidor de Costa Rica y México. Sin embargo, en este caso la monopolización del mercado mundial atenúa el problema para Costa Rica.

Lo importante en lo que toca a este sector es que, ingrese o no China a la OMC, la eliminación de cuotas en el mercado estadounidense para los productos de la confección es inevitable; al parecer, los grandes favorecidos serían los países del sur de Asia y los más perjudicados los de la cuenca del Caribe y, en menor medida, México. La incorporación de China a la oMC vendría a agudizar aún más la situación planteada, pues le daría mayor acceso al mercado estadounidense y así restringiría incluso más las posibilidades de crecimiento de los países de la cuenca. Por otra parte, como hemos dicho antes, éstos se han visto beneficiados recientemente con la ampliación de beneficios comerciales.

En síntesis, los países de la cuenca tienen una "ventana" de oportunidades entre el 2000 y el 2005 que deberán aprovechar para reestructurar su sector textil y de la confección con miras a tomar la delantera. Esto tiene implicaciones que no es del caso desarrollar aquí, pero llama a reflexión acerca de la necesidad de ordenar las políticas de apoyo al sector y las bases mismas de la atracción de inversiones.

En el rubro del calzado, China representa una fuerte competencia para la República Dominicana y, además, tiene la posibilidad de vender a precios más bajos, como lo ha venido haciendo hasta el momento; por lo tanto, un incremento de las relaciones comerciales entre los Estados Unidos y China podría tener efectos adversos sobre la evolución de las importaciones de este tipo desde la República Dominicana.

En "Otros instrumentos de uso médico", China es un competidor importante para las exportaciones de la República Dominicana y Costa Rica a los Estados Unidos, por lo que habría que mirar con atención las posibilidades que tiene China de ampliar sus exportaciones 
en este campo. En cuanto a las "partes de máquinas automáticas", China no parece ser un competidor importante de Costa Rica, dado que solamente abastece a un $0.2 \%$ del mercado estadounidense.

De lo dicho se desprende que los sectores de la cuenca del Caribe que podrían verse más afectados por la entrada de China a la OMC serían el de la confección y el del calzado.

Por último, cabe destacar que los países de la cuenca - $-\mathrm{y}$ del resto del continente americano- deberían percibir la ampliación de las preferencias de la Iniciativa para la cuenca del Caribe como la primera buena señal práctica que envía Estados Unidos sobre sus posibilidades de negociar el Area de Libre Comer- cio de las Américas. En el caso particular de los países de la cuenca, la legislación señala que el presidente de los Estados Unidos deberá tomar todas las medidas necesarias para establecer un calendario de reuniones entre los ministros de comercio de los países de la cuenca y el Representante de Comercio de los Estados Unidos, con el fin de llegar a un acuerdo entre este país y los de la ICC que sea ventajoso para ambas partes y contenga provisiones similares a las del TLC de América del Norte. De esta forma, las puertas quedan abiertas para que los países de la cuenca inicien negociaciones con el gobierno estadounidense para llegar a un acuerdo por el cual la paridad con ese tratado se vuelva una realidad.

\section{Bibliografía}

Arias, C. (1999): Guatemala busca alternativas competitivas, Georgia, Apparel Industry International, septiembre-octubre.

Banco Mundial (1999): World Development Indicators, 1999, Washington, D.C.

Bates, G. (1999): Limited engagement, Foreign Affairs, vol. 78, № 4, Nueva York, Council on Foreign Affairs.

Bosworth, P. y G. Ofer (1995): Reforming planned economies, An Integrating World Economy, Washington, D.C., The Brookings Institution.

Chacón, F. (2000): Comercio internacional de los textiles y el vestido: reestructuración global de las fuentes de oferta en los EE.UU. durante la década de los años noventa, Integración y comercio, año $4, \mathrm{~N}^{\circ} 11$, Washington, D.C., Banco Interamericano de Desarrollo (BID).

Comisión de Comercio Internacional (1999a): Industry and Trade Summary: Apparel, Publication $\mathrm{N}^{\circ} 3169$, Washington, D.C., marzo.

(1999b): Assessment of the Economic Effects on the United States of China's Accession to the WTO, Investigation $\mathrm{N}^{\circ}$ 332-403, Washington, D.C., septiembre.

(1999c): Production Sharing: Use of U.S. Components and Materials in Foreign Assembly Operations, 1995-1998, Investigation $\mathrm{N}^{\circ} 332-237$, Washington, D.C., diciembre.

Economy, E. (1999): Painting China green, Foreign Affairs, vol. 78, $\mathrm{N}^{\circ} 2$, Nueva York, Council on Foreign Affairs.

Elliot, R. (2000): Argentina Sees Fatter Farm Export with China, Reuters, 22 de marzo.

FMI (Fondo Monetario Internacional) (2000a): Balance of Payment Statistics, Washington, D.C. D.C.

(2000b): International Financial Statistics, Washington,

GAO (General Accounting Office) (2000): World Trade Organization. China's Membership Status and Normal Trade Relations Issues, Washington, D.C.

Gereffi, G. (2000): La transformación de la industria de la indumentaria en América del Norte. ¿Es el TLCAN una maldición o una bendición?, Integración y comercio, año $4, \mathrm{~N}^{\circ} 11$, Washington, D.C., BID.

Gitli, E. (1997): La industria de la maquila en Centroamérica, San José, Costa Rica, Organización Internacional del Trabajo (OIT), diciembre.
Gitli, E. y R. Arce (2000a): Los desbalances de los países de la cuenca del Caribe frente al TLCAN: la industria de la confección, Integración y comercio, año $4, \mathrm{~N}^{\circ} 11$, Washington, D.C., BID. (2000b): ¿Qué significa para la cuenca del Caribe la ampliación de preferencias comerciales de EE.UU.?, Capítulos, $\mathrm{N}^{\circ}$ 59, Caracas, Sistema Económico Latinoamericano (SELA).

Lardy, N. (2000): Permanent Normal Trade Relations for China, Policy Brief $\mathrm{N}^{\circ} 58$, Washington, D.C., The Brookings Institution, mayo.

Lin, J. Y., F. Cai y Z. Li (1998): Competition, policy burdens, and state-owned enterprise reform, The American Economic Review, vol. 88, $\mathrm{N}^{\circ}$ 2, Nashville, Tennessee, American Economic Association.

Mody, A. y F. Wang (1997): Explaining industrial growth in coastal China: Economic reforms ... and what else?, The World Bank Economic Review, vol. 11, N² 2, Washington, D.C., Banco Mundial.

Naciones Unidas (1999): Estudio económico y social mundial 1999. Tendencias y políticas en la economía mundial, Nueva York. Publicación de las Naciones Unidas, $\mathrm{N}^{\circ}$ de venta S.99.II.C.1.

Ng, F. y A. Yeats (1999): Production Sharing in East Asia: Who Does What for Whom and Why?, Washington, D.C., Banco Mundial, Trade Team, Development Research Group.

OMC (Organización Mundial del Comercio) (2000): China's accession to the WTO, www.wto.org/wto/about/china.html

Public Citizen (1999): Clarifying the rules on WTO accession. China and MFN status, Washington, D.C., Public Citizen Global Trade Watch, 24 de mayo.

The Economist (1997): A survey of China: Ready to face the world?, Londres, The Economist Newspaper, NA, Inc., marzo.

The Journal of Commerce (2000a): China should listen, The Journal of Commerce Online, 4 de febrero, http://www.joc.com

(2000b): Time runs down on China Pact, The Journal of Commerce Online, 18 de febrero, http://www.joc.com

(2000c): Clinton's biggest battle this year: trade, The Journal of Commerce Online, 23 de febrero, http://www.joc.com

UNCTAD (Conferencia de las Naciones Unidas sobre Comercio y Desarrollo) (1999): World Investment Report 1999: Foreign Direct Investment and the Challenge of Development, Nueva York. 
Unión Europea (2000): The sino-EU agreement on China's accession to the WTO: Results of the bilateral negotiations, Bruselas, mayo, www.europa.eu.int

US-China Business Council (2000): Copy of U.S.-China Bilateral Market Agreement as Released by USTR on March 14, 2000, Washington, D.C., http://www.uschina.org
White House (2000): Summary of U.S.-China Bilateral WTO Agreement, Washington, D.C., China Trade Relations Working Group, 2 de febrero.

Zúñiga, C. (1999): El Salvador se enfoca en el paquete completo, Georgia, Apparel Industry International, Bill Communications, noviembre-diciembre. 